Check for updates

Cite this: RSC Adv., 2018, 8, 23489

Received 7th May 2018

Accepted 12th June 2018

DOI: $10.1039 / \mathrm{c} 8 \mathrm{ra03890b}$

rsc.li/rsc-advances

\section{Visible light assisted photocatalytic degradation of crystal violet dye and electrochemical detection of ascorbic acid using a $\mathrm{BiVO}_{4} / \mathrm{FeVO}_{4}$ heterojunction composite $\uparrow$}

\author{
Muhammad Munir Sajid, ${ }^{\text {ac }}$ Sadaf Bashir Khan, (D) Naveed Akthar Shad, ${ }^{\text {ab }}$ \\ Nasir Amin (D) and Zhengjun Zhang (D) *d
}

\begin{abstract}
A BiVO ${ }_{4} / \mathrm{FeVO}_{4}$ nanocomposite photocatalyst was successfully synthesized via a hydrothermal method. The prepared heterojunction photocatalyst was characterized physically and chemically using XRD, SEM, EDX, XPS, BET, FT-IR, Raman, UV-vis DRS, EPR and photoluminescence techniques. BiVO ${ }_{4} / \mathrm{FeVO}_{4}$ was explored for its photocatalytic activity by the decomposition of crystal violet $(\mathrm{CV})$ organic dye under visible radiation. This experiment showed that $\mathrm{BiVO}_{4} / \mathrm{FeVO}_{4}$ at a ratio of $2: 1$ completely degrades $\mathrm{CV}$ within 60 min. In addition, $\mathrm{BVO}_{4} / \mathrm{FeVO}_{4}$ was investigated for the electrochemical detection of the useful analyte ascorbic acid using electrochemical impedance spectroscopy (EIS) and cyclic voltammetry techniques. This work reveals the potential of the $\mathrm{BiVO}_{4} / \mathrm{FeVO}_{4}$ nanocomposite for applications in environmental disciplines as well as in biosensing.
\end{abstract}

\section{Introduction}

The large-scale disposal of dyes from fabrics, plastics, cosmetics, paper, leather, food, municipal waste and other industries into the water poses a significant threat to the environment. Approximately $1-20 \%$ of the dye produced globally is lost during the dyeing process and is expelled in waste water. ${ }^{1-5}$ These dyes are major causes of water pollution, so it is urgent that we develop either facile methods or eco-friendly techniques to treat polluted water and make it usable for human beings and other living organisms. A lot of work has been conducted in this area, involving approaches including filtration, electrochemical methods, precipitation, coagulation and adsorption, which are all common techniques for water remediation. ${ }^{6}$ Among these processes, heterogeneous photocatalysis is an advanced oxidant process (AOP) that has emerged in recent years. AOPs are used extensively as a facile and cost-effective way to mineralize pollutant water without generating secondary harmful

${ }^{a}$ Department of Physics, Government College University, Allama Iqbal Road, Faisalabad, 38000, Pakistan

${ }^{b}$ National Institute for Biotechnology and Genetic Engineering (NIBGE), P. O. Box. 577, Jhang Road, Faisalabad, Pakistan

'The State Key Laboratory for New Ceramics \& Fine Processing, School of Materials Science \& Engineering, Tsinghua University, Beijing, China, 100084

${ }^{d A}$ Advanced Key Laboratory for New Ceramics, School of Materials Science \& Engineering, Tsinghua University, Beijing, China, 100084. E-mail: zjzhang@ tsinghua.edu.cn

$\dagger$ Electronic supplementary information (ESI) available. See DOI: $10.1039 / \mathrm{c} 8 \mathrm{ra03890b}$ pollutants, by using light in the presence of a catalyst. ${ }^{7-9}$ The effectiveness of an AOP is proportional to its ability to generate hydroxyl radicals. Photocatalysis is based on the principle in which the absorption of sunlight energy produces electrons and holes to activate oxidation-reduction responses on the surface of a semiconductor to degrade particular compounds.

Metallic oxide (MO) semiconductors are generally considered as photocatalysts, but because of their wide band gaps, the light absorption ability of binary MOs is limited, affecting their photocatalytic efficiency. Therefore, it is necessary to fabricate MOs with smaller band gaps for effective employment of solar energy. To this end, ternary metal oxides (TMOs), which have valence bands made from orbitals of more than one element, come forward. TMOs have narrow band gaps with high visible light illumination absorption ability. Among these TMOs, metal vanadate is of great importance in several areas including photocatalysis, catalysis and batteries. ${ }^{10-13}$ One of the various metal vanadates that a lot of effort has been devoted to synthesizing and characterizing is bismuth vanadate $\left(\mathrm{BiVO}_{4}\right)$, owing to its good optical, conductivity and ferroelasticity properties. It is used in yellow pigments, $\mathrm{O}_{2}$ evaluation, degradation of pollutants, electrodes for batteries and gas sensors. ${ }^{14-17}$

Bismuth vanadate was first reported as a photocatalyst in 1998 for water splitting by Kudo and Ueda, with the monoclinicscheelite $\left(\mathrm{m}-\mathrm{BiVO}_{4}\right)$ phase showing the highest efficiency. In the next year, Kudo's group described the increased visible radiation photocatalytic attributes of $\mathrm{BiVO}_{4}$ for $\mathrm{O}_{2}$ evolution in an aqueous silver nitrate solvent. In another exciting investigation 
reported by Kudo et al., monoclinic and tetragonal $\mathrm{BiVO}_{4}$, which both have a scheelite structure, and the same composition, components and energy structure, showed extensively divergent photocatalytic efficiencies for $\mathrm{O}_{2}$ evolution in an $\mathrm{AgNO}_{3}$ mixture under ultraviolet and visible light, owing to the distortion of the $\mathrm{Bi}-\mathrm{O}$ polyhedron due to the $6 \mathrm{~S}_{2}$ lone pairs of $\mathrm{Bi}^{3+} \cdot{ }^{\mathbf{1 8 - 2 0}}$

Fabricating heterojunction photocatalysts based on various semiconductor materials represents an economical process to aid the separation of photo-excited charges (electron-hole pairs (ehps)) and increase the photocatalytic properties. ${ }^{21}$ Heterojunction photocatalysts are manufactured in several different ways, including sol-gel synthesis, ball milling, ${ }^{22}$ hydrothermal synthesis $^{23}$ and co-precipitation, ${ }^{24}$ which lead to a heterojunction photocatalyst with an improved photocatalytic response as compared to that of its single ingredients. From a literature survey, it was found that heterojunction photocatalysts such as $\mathrm{InVO}_{4} / \mathrm{BiVO}_{4}, \mathrm{CuO} / \mathrm{BiVO}_{4}, \mathrm{C}_{3} \mathrm{~N}_{4} / \mathrm{BiVO}_{4}, \mathrm{BiVO}_{4} /$ $\mathrm{Bi}_{2} \mathrm{~S}_{3}$ and $\mathrm{CaFe}_{2} \mathrm{O}_{4} / \mathrm{Ag}_{3} \mathrm{VO}_{4}$ exhibit higher photocatalytic efficiency compared to single semiconductors. ${ }^{25-29}$ When a large band gap semiconductor is combined with a short band gap semiconductor, the electron-hole separation is prolonged and a superior photocatalytic response is achieved. ${ }^{22}$

To the best of our knowledge, there are few reports in the literature regarding the use of $\mathrm{BiVO}_{4} / \mathrm{FeVO}_{4}$ nanostructured heterojunction composites for the photocatalytic degradation of crystal violet dye, as well as the electrochemical detection of ascorbic acid. In this study, a $\mathrm{BiVO}_{4} / \mathrm{FeVO}_{4}$ heterojunction composite was prepared via a hydrothermal method. Both $\mathrm{BiVO}_{4}$ and $\mathrm{FeVO}_{4}$ are earth-abundant minerals with narrow band gaps and show innate visible light absorption at around $600 \mathrm{~nm}$ at about $2.05 \mathrm{eV}$. Therefore, combining $\mathrm{BiVO}_{4}$ and $\mathrm{FeVO}_{4}$ can increase the extent of electron and hole separation and enhance the photocatalytic process. The as-synthesized $\mathrm{BiVO}_{4} / \mathrm{FeVO}_{4}$ nanocomposite was investigated using XRD, SEM, EDS, XPS, BET, UV-vis and photoluminescence techniques for physical and chemical behavior studies. The photocatalytic response of the as-synthesized nanocomposite was evaluated by investigating the degradation of crystal violet (CV) dye under visible light. The electrochemical properties of the $\mathrm{BiVO}_{4} / \mathrm{FeVO}_{4}$ nanocomposite were also investigated for the detection of the important analyte ascorbic acid. This work exposes the potential of the $\mathrm{BiVO}_{4} / \mathrm{FeVO}_{4}$ nanocomposite for applications in environmental science as well as biosensor domains.

\section{Experimental methods}

All of the materials were of analytical grade and used without any purification. The heterojunction composite $\mathrm{BiVO}_{4} / \mathrm{FeVO}_{4}$ was fabricated via a hydrothermal method. Firstly, $1 \mathrm{mmol}$ $\mathrm{Bi}\left(\mathrm{NO}_{3}\right)_{3} \cdot 5 \mathrm{H}_{2} \mathrm{O}$ and $1 \mathrm{mmol} \mathrm{Fe}\left(\mathrm{NO}_{3}\right)_{3} \cdot 9 \mathrm{H}_{2} \mathrm{O}$ were dissolved in $60 \mathrm{~mL}$ distilled water, then $2 \mathrm{mmol}$ of $\mathrm{NH}_{4} \mathrm{VO}_{3}$ was poured into the solution and vigorous stirring was carried out for $1 \mathrm{~h}$ at ambient temperature. The $\mathrm{pH}$ was adjusted to around $8 \mathrm{using}$ $\mathrm{NaOH}$, and the solution was transferred into a $100 \mathrm{~mL}$ Teflonlined stainless autoclave, which was heated at $180{ }^{\circ} \mathrm{C}$ for $24 \mathrm{~h}$. After cooling the autoclave, the precipitate was centrifuged and washed many times with ethanol and distilled water. It was then dried at $80{ }^{\circ} \mathrm{C}^{30,31}$ To check the effects of various concentrations on the crystallinity, morphology, photocatalytic and electrochemical sensing properties, $\mathrm{BiVO}_{4} / \mathrm{FeVO}_{4}$ heterojunctions were prepared in different molar ratios while keeping all other parameters the same, resulting in gradual color changes from blackish to yellowish as the $\mathrm{BiVO}_{4}$ concentration increased. The flow chart of the preparation method is shown in Fig. 1.

\section{Characterization of $\mathrm{BiVO}_{4} / \mathrm{FeVO}_{4}$}

A Rigaku 2500 X-ray diffractometer was used to analyze the crystallinity, phase and particle size of the synthesized nanoparticles. The morphological features and topography were characterized using field emission scanning electron microscopy, on a JEOL-7001F working at an operating voltage of $20 \mathrm{kV}$. The elemental analysis of the nanoparticles was examined using energy-dispersive X-ray spectroscopy (EDX), with an FESEM microscope attached to an XPS spectrometer (PHI 5000 Versa Probe). The absorbance spectra of organic $\mathrm{CV}$ dye were measured using a PerkinElmer $\lambda-35$ UV-vis spectrophotometer. The porosity and Brunauer-Emmett-Teller (BET) surface areas of the products were evaluated by a multi-point BET method using adsorption data. FT-IR measurements were obtained on a Nicolet Magna-550 spectrometer. Photoluminescence (PL) and Raman analysis were conducted on Horiba Scientific Fluoromax-4 spectrofluorometer. Electronic Paramagnetic Resonance (EPR) analysis was performed on an ESR-JES-FA 2010 spectrometer.

\section{Photocatalytic activity}

To check the photocatalytic responses of powdered $\mathrm{BiVO}_{4} /$ $\mathrm{FeVO}_{4}$, samples were illuminated using a UV-visible light xenon lamp with an accumulative intensity of $300 \mathrm{~W}$ for degrading CV

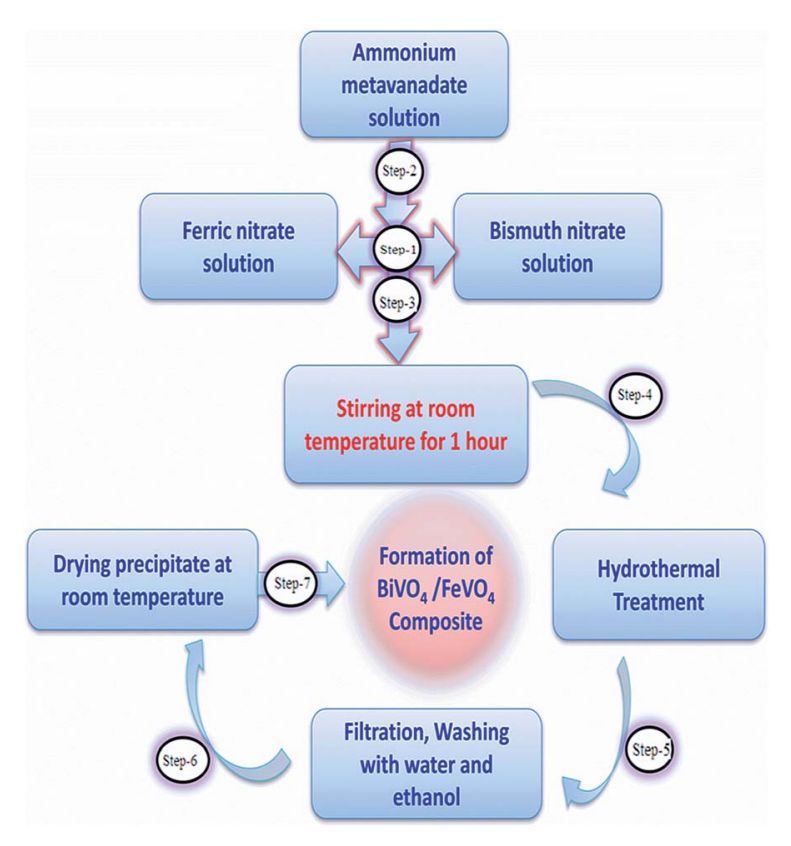

Fig. 1 Flow chart of the hydrothermal method for the preparation of $\mathrm{BiVO}_{4} / \mathrm{FeVO}_{4}$ 
dye, which was $25 \mathrm{~cm}$ away from the lamp. For studying the kinetics, dye solutions with fixed concentrations $(150 \mathrm{~mL})$ at neutral $\mathrm{pH}$ were prepared and $0.1 \mathrm{~g}$ of the prepared $\mathrm{BiVO}_{4} /$ $\mathrm{FeVO}_{4}$ photocatalyst was mixed into each separate solution. The $\mathrm{pH}$ was maintained by adding $\mathrm{HNO}_{3}$ and $\mathrm{NaOH}$, and then each prepared solution was stirred for 15 min in the dark and finally centrifuged at $10000 \mathrm{rpm}$ for $5 \mathrm{~min}$. To avoid any thermal degradation and to keep the temperature at $0{ }^{\circ} \mathrm{C}$, nitrogen cooling was used throughout the experiment. ${ }^{32}$ The degradation phenomenon of the dye was analyzed using a PerkinElmer $\lambda-35$ UV-vis spectrometer in the spectral range of $400-800 \mathrm{~nm}$.

\section{Sensor measurements}

The electrochemical evaluation was carried using a model Chi760D electrochemical work station, and a three-electrode scheme. A glassy carbon electrode (GCE) was applied in this work for electrode adjustment. $\mathrm{BiVO}_{4} / \mathrm{FeVO}_{4}(0.5 \mathrm{mg})$ was first dispersed in $1 \mathrm{~mL}$ distilled water. Then, $10 \mu \mathrm{L}$ of nanomaterial was put on the GC electrodes and dehydrated in the oven at $80{ }^{\circ} \mathrm{C}$ for $2 \mathrm{~min}$, after which $2-3 \mu \mathrm{L}$ of $5 \%$ Nafion was dropcasted onto the electrodes and dried out. Each solution for sensor measurements comprised distilled water, and the required concentrations were made up using suitable dilutions from the respective stock solutions. The $\mathrm{BiVO}_{4} / \mathrm{FeVO}_{4}$ modified glassy electrode was applied as the working electrode, a carbon glassy rod as the counter electrode and $\mathrm{Ag} / \mathrm{AgCl}$ electrode as the reference electrode. Before the electrochemical measurements, each solution was degassed using nitrogen gas for 4-5 min. Electrochemical impedance spectroscopy (EIS) was carried out at an amplitude of $0.01 \mathrm{~V}$ in the frequency range of $0.1-4000 \mathrm{~Hz}$. Cyclic voltammetry measurements were recorded in the potential range of $-1.0 \mathrm{~V}$ to $+1.0 \mathrm{~V}$ at a scan rate of $0.05 \mathrm{~V} \mathrm{~s}^{-1}$ in a mixed solution of $0.1 \mathrm{M} \mathrm{H}_{3} \mathrm{PO}_{4}, \mathrm{Li}_{2} \mathrm{SO}_{4}, \mathrm{NaSO}_{4}$ and $\mathrm{NaOH}$ with ascorbic acid at $0.05 \mathrm{mM}$ concentration. All measurements were executed at room temperature.

\section{Results and discussion}

Fig. 2a shows the XRD diffraction pattern of the as-prepared $\mathrm{BiVO}_{4} / \mathrm{FeVO}_{4}$ nanophotocatalysts at different concentration ratios for phase structures. The XRD diffraction peaks of $\mathrm{BiVO}_{4} /$ $\mathrm{FeVO}_{4}$ are in agreement with pure $\mathrm{BiVO}_{4}$ (JCPD card 85-1730) ${ }^{33}$ and $\mathrm{FeVO}_{4}$ (JCPD card 24-0541). The patterns of the $\mathrm{BiVO}_{4} /$ $\mathrm{FeVO}_{4}$ heterojunction photocatalyst compounds display typical diffraction peaks from both $\mathrm{BiVO}_{4}$ and $\mathrm{FeVO}_{4}$ distinct phases, verifying that the $\mathrm{BiVO}_{4} / \mathrm{FeVO}_{4}$ nanocomposites at different molar ratios were prepared successfully by the autoclave hydrothermal process, as shown in Fig. 2a. The intense and edged peaks of $\mathrm{BiVO}_{4}$ suggest a larger crystallite size, while the small peaks of $\mathrm{FeVO}_{4}$ indicate a small particle size. There is a shift in the peaks (Fig. 2b) first towards the left when the ratio is $2: 1$, and then towards the right as the ratio increases from $5: 1$ to $10: 1$. The color also changes gradually into yellowish as the $\mathrm{BiVO}_{4}$ concentration is increased. It can be clearly observed that the broadening of $\mathrm{BiVO}_{4}$ peaks takes place and the intensity of the $\mathrm{FeVO}_{4}$ peaks declines. Here, the optimum conditions
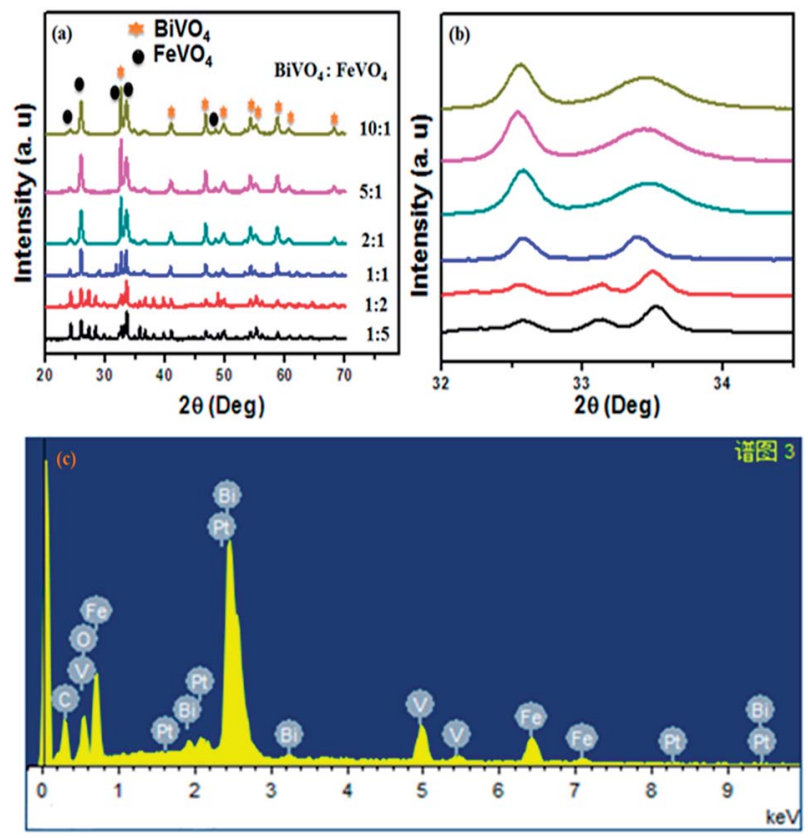

Fig. 2 (a) XRD spectrum of $\mathrm{BiVO}_{4} / \mathrm{FeVO}_{4}$ composite heterojunction photocatalysts at different molar ratios of $1: 5,1: 2,1: 1,2: 1,5: 1$ and 10 : 1. (b) Peak shifts in the XRD spectrum of $\mathrm{BiVO}_{4} / \mathrm{FeVO}_{4}$ due to increasing concentration of $\mathrm{BiVO}_{4}$. (c) EDS analysis of $\mathrm{BiVO}_{4} / \mathrm{FeVO}_{4}$ composite at a molar ratio of $2: 1$.

were revealed for making $\mathrm{BiVO}_{4} / \mathrm{FeVO}_{4}(2: 1)$ at which high intensity peaks are found, as indicated in Fig. 2a. From the EDS analysis shown in Fig. 2c, it is observed that the elements vanadium, iron, bismuth and oxygen are homogeneously spread throughout the composite, and the presence of carbon and platinum peaks are due to carbon tape and platinum coating. Aside from this, no impurities were detected within the detection limit.

The surface topography and morphological analysis of the $\mathrm{BiVO}_{4} / \mathrm{FeVO}_{4}$ nanocomposites were characterized using field emission scanning electron microscopy, on a JEOL-7001F. SEM images of the composites at different ratios $(1: 5,1: 2,1: 1$, $2: 1,5: 1$ and $10: 1$ ) are illustrated in Fig. 3a-f. It was noticed that at higher concentrations of $\mathrm{FeVO}_{4}$, small sized nanocomposites developed, as shown in Fig. 3a and b. When the $\mathrm{BiVO}_{4} / \mathrm{FeVO}_{4}$ ratio was $1: 5$, rod and particle shaped nanostructures formed, while at a ratio of $1: 2$, polyhedron and particle shaped nanostructures formed. In the opposite case, upon increasing the molar ratio of $\mathrm{BiVO}_{4}$ in the $\mathrm{BiVO}_{4} / \mathrm{FeVO}_{4}$ nanocomposite, large crystallite sizes were found, as shown in Fig. 3d-f. In Fig. 3d the $\mathrm{BiVO}_{4} / \mathrm{FeVO}_{4}$ nanocomposite at a molar ratio of $2: 1$ comprises rods and plates, and some plates are linked with each other to form chains that look like flower type structures. At a molar ratio of $5: 1$, the SEM image captured shows rod and plate-like structures, in which there are more agglomerations of plates than at the previous concentration ratio. The SEM image in Fig. 3f of the $\mathrm{BiVO}_{4} / \mathrm{FeVO}_{4}$ nanocomposite at a molar ratio $10: 1$ shows flowers and just a few plate structures are found. 

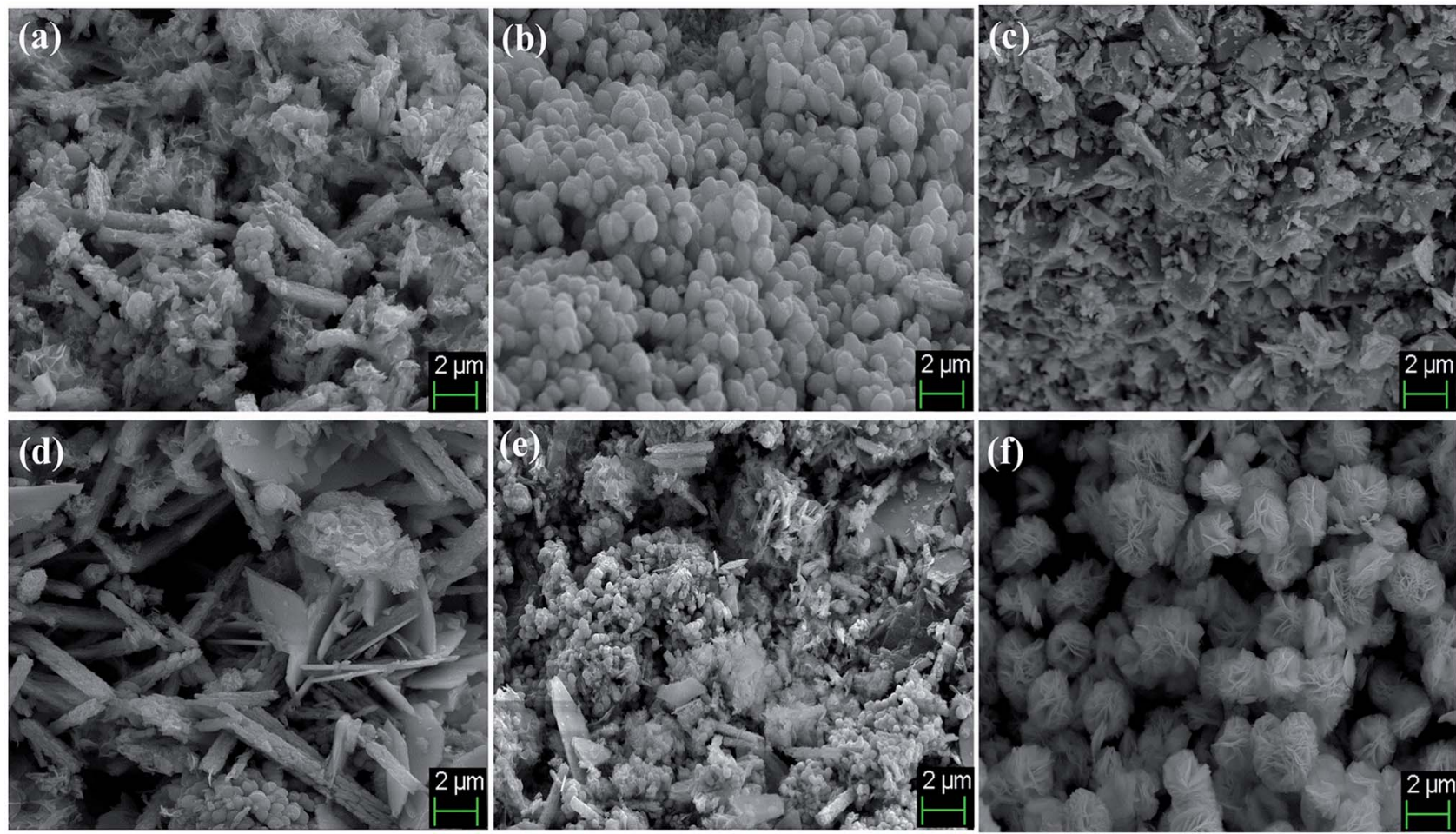

Fig. 3 SEM images of $\mathrm{BiVO}_{4} / \mathrm{FeVO}_{4}$ composite heterojunction photocatalysts at different molar ratios of (a) $1: 5$, (b) $1: 2$, (c) $1: 1$, (d) $2: 1$, (e) $5: 1$ and (f) $10: 1$.

The SEM morphologies of pure $\mathrm{BiVO}_{4}$ and $\mathrm{FeVO}_{4}$ are given in Fig. S1 (ESI). $\dagger$ The formation and conversion from particles to nanorods and flower shape morphologies are totally dependent on the experimental conditions, reaction mechanisms and material compositions. In our experimental results, rod and particle shaped nanostructure formation occurs when the $\mathrm{FeVO}_{4}$ concentration is higher than that of $\mathrm{BiVO}_{4}$. Contrarily, as the $\mathrm{BiVO}_{4}$ concentration increases, plate-like crystallites begin to appear, ultimately forming flower shaped nanostructures. These morphological changes take place due to differences in structure, atomic radii, crystal orientation and reactions occurring during the hydrothermal synthesis. Thus, our experimental results validate that nanorod and particle conversion into nanoplate flower-like morphologies takes place as the ratio of $\mathrm{BiVO}_{4}$ and $\mathrm{FeVO}_{4}$ is changed during the synthesis of the $\mathrm{BiVO}_{4} / \mathrm{FeVO}_{4}$ nanocomposites, as shown in the SEM image (Fig. 3).

X-ray photoelectron spectroscopy (XPS) is a surface analysis method for investigating the composition and chemical states of the constituents. In order to validate further, elemental analysis was carried out by performing XPS characterization. Fig. 4a shows the typical X-ray photoelectron spectrum of the $\mathrm{BiVO}_{4} / \mathrm{FeVO}_{4}$ nanocomposite, which is composed of $\mathrm{O}, \mathrm{Bi}, \mathrm{V}$, and Fe. In the XPS analysis of the $2: 1 \mathrm{BiVO}_{4} / \mathrm{FeVO}_{4}$ nanocomposite, two peaks of oxygen at $1 \mathrm{~s}$ are located at 530.6 and $531.8 \mathrm{eV}^{34,35}$ in Fig. 4 b, showing the two different peaks of $\mathrm{O}_{2}$ in the experiment. Two peaks of $\mathrm{V} 2 \mathrm{p}_{3 / 2}$ at $517.41 \mathrm{eV}$ and $\mathrm{V} 2 \mathrm{p}_{1 / 2}$ at $524.12 \mathrm{eV}$ were noticed, as shown in Fig. 4c. Fig. 4d highlights the XPS peaks of $B i 4 f_{7 / 2}$ and $B i 4 f_{5 / 2}$, which are found at $159.44 \mathrm{eV}$ and $164.68 \mathrm{eV}^{36}$ In Fig. 4e, the Fe 2p spectrum comprises two leading peaks $\left(2 \mathrm{p}_{1 / 2}\right.$ and $\left.2 \mathrm{p}_{3 / 2}\right)$ with many subpeaks, with the main peaks positioned at 711.27 and $725.19 \mathrm{eV}{ }^{37}$ A peak shift was found similar to that observed in the XRD analysis, which may be attributed to morphology effects or the increasing concentration of $\mathrm{BiVO}_{4}$. From the above XRD and XPS detailed spectra, the formation of the $\mathrm{BiVO}_{4} /$ $\mathrm{FeVO}_{4}$ heterojunction photocatalysts can be confirmed.

The $\mathrm{N}_{2}$ sorption isotherms of the $2: 1$ nanocomposite photocatalyst $\mathrm{BiVO}_{4} / \mathrm{FeVO}_{4}$ were produced and examined. The Brunauer-Emmett-Teller surface area was found to be 70.147 $\mathrm{cm}^{2} \mathrm{~g}^{-1}$. The pore size was estimated from the desorption isotherms, using the Barret-Joyner-Halender (BJH) method..$^{38,39}$ The evaluated pore volume and average pore diameter were found to be $0.124 \mathrm{~cm}^{3} \mathrm{~g}^{-1}$ and $3.798 \mathrm{~nm}$, respectively, as shown in Fig. 5. The adsorption curve is a type III curve presenting the hysteresis of $\mathrm{H}_{2}$ and $\mathrm{H}_{3}$ types, which associates slit shape capillaries with large and narrow short plate-like aggregates of particles, resulting in a lamellar pore structure and slit shaped pores. ${ }^{40}$ The lamellar wedge shaped pore construction clearly indicates the presence of mesopores within the structure.

The Brunauer-Emmett-Teller surface areas of the $\mathrm{BiVO}_{4} /$ $\mathrm{FeVO}_{4}$ composites at molar ratios of $1: 5,1: 2,1: 1,5: 1$ and $10: 1$ were $136.188,6.019,7.097,9.325$ and $14.679 \mathrm{~cm}^{2} \mathrm{~g}^{-1}$, the pore volumes were $0.213,0.010,0.012,0.013$ and $0.025 \mathrm{~cm}^{3} \mathrm{~g}^{-1}$, and the pore diameters were 1.682, 1.932, 1.682, 1.937 and $2.181 \mathrm{~nm}$, respectively, as shown in Fig. S2 (ESI). $\dagger$

Fig. 6a shows the FT-IR spectra of the $\mathrm{BiVO}_{4} / \mathrm{FeVO}_{4}$ heterogeneous composites prepared under different molar ratios, where the absorption from 3000 to $3600 \mathrm{~cm}^{-1}$ is due to the stretching vibration of $\mathrm{OH}$ of absorbed water. The absorption at 

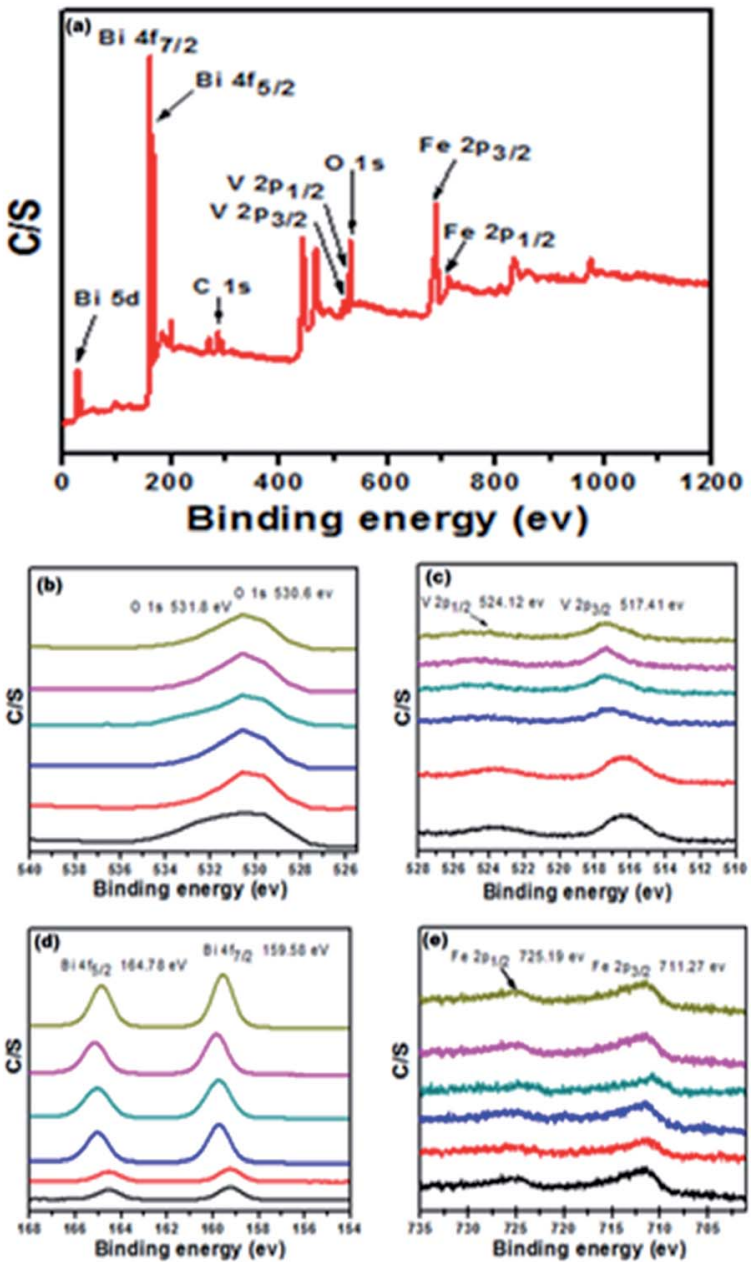

Fig. 4 XPS of $\mathrm{BiVO}_{4} / \mathrm{FeVO}_{4}$ nanocomposite at different molar ratios of $\mathrm{BiVO}_{4}$ and $\mathrm{FeVO}_{4}$.

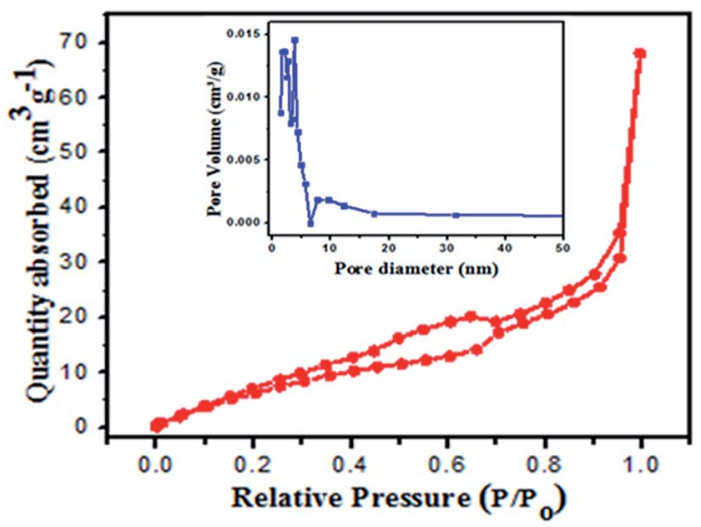

Fig. 5 BET surface area (inset pore diameter) of the $2: 1 \mathrm{BiVO}_{4} / \mathrm{FeVO}_{4}$ composite at $77.35 \mathrm{~K}$.

$1631 \mathrm{~cm}^{-1}$ is due to absorbed water molecule bending vibration. The band at $512 \mathrm{~cm}^{-1}$ is due to $\mathrm{V}-\mathrm{O}-\mathrm{V}$ deformation caused by the $\mathrm{V}-\mathrm{O}$ stretching mode. The peaks at 741, 837, 915 and $1052 \mathrm{~cm}^{-1}$ correspond to $\mathrm{V}=\mathrm{O}$ and $\mathrm{V}-\mathrm{O}-\mathrm{V}$ joined vibrations and the stretching of the short vanadyl bond, while the $\mathrm{Bi}-\mathrm{O}$
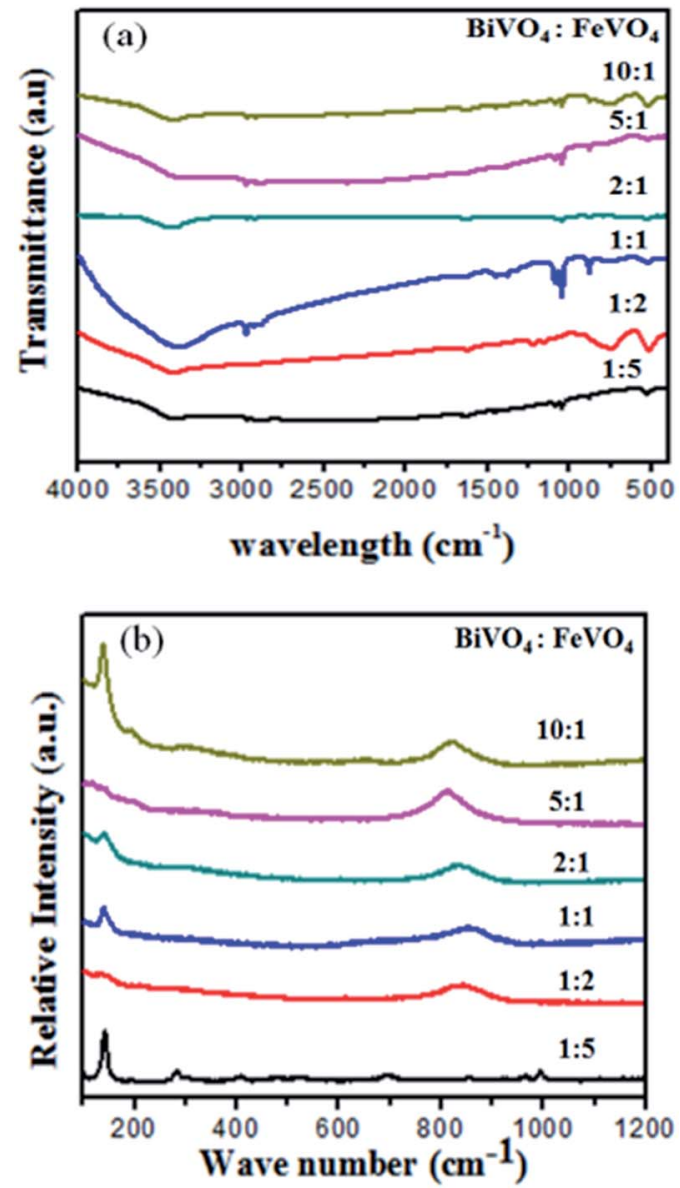

Fig. 6 (a) FT-IR spectra and (b) Raman spectra of the $\mathrm{BiVO}_{4} / \mathrm{FeVO}_{4}$ heterogeneous composites prepared with different molar ratios.

bending and asymmetric vibrations appear at $474 \mathrm{~cm}^{-1}$ and $1362 \mathrm{~cm}^{-1}$, respectively. ${ }^{41-45}$

Raman analysis is a useful tool for providing structural information and is also a sensitive method for investigating crystallization, local structure and the electronic dimensions of materials. In Fig. 6b, Raman bands at around 198, 333, 367, 640 and $836 \mathrm{~cm}^{-1}$ corresponding to $\mathrm{BiVO}_{4}$ were observed for all samples, while bands at around 139, 300, 354, 655, 962 and $996 \mathrm{~cm}^{-1}$ represent $\mathrm{FeVO}_{4}$ in the samples. ${ }^{46-48}$ A shift in the peaks was observed as the molar ratio changed. At higher concentrations of $\mathrm{BiVO}_{4}$, the peaks were broader and covered the $\mathrm{FeVO}_{4}$ peaks, as observed in the XRD and XPS analysis, which also confirms and supports our previous results.

\section{Photocatalytic activity of crystal violet solution}

To determine the photocatalytic activity of $\mathrm{FeVO}_{4}, \mathrm{BiVO}_{4}$ and the $\mathrm{BiVO}_{4} / \mathrm{FeVO}_{4}$ nanophotocatalysts, the degradation rate of $\mathrm{CV}$ dye was investigated in water under visible radiation from $400<\lambda<800 \mathrm{~nm}$. The chemical formula of CV is $\mathrm{C}_{25} \mathrm{H}_{30} \mathrm{ClN}_{3}$, and its chemical structure with its adsorption spectrum is shown in Fig. S3 (ESI). $\dagger$ The photocatalytic response of the $\mathrm{BiVO}_{4} / \mathrm{FeVO}_{4}$ photocatalysts is shown in Fig. S4 (ESI). $\dagger$ It is noticed that the photocatalytic action of $2: 1 \mathrm{BiVO}_{4} / \mathrm{FeVO}_{4}$ is 

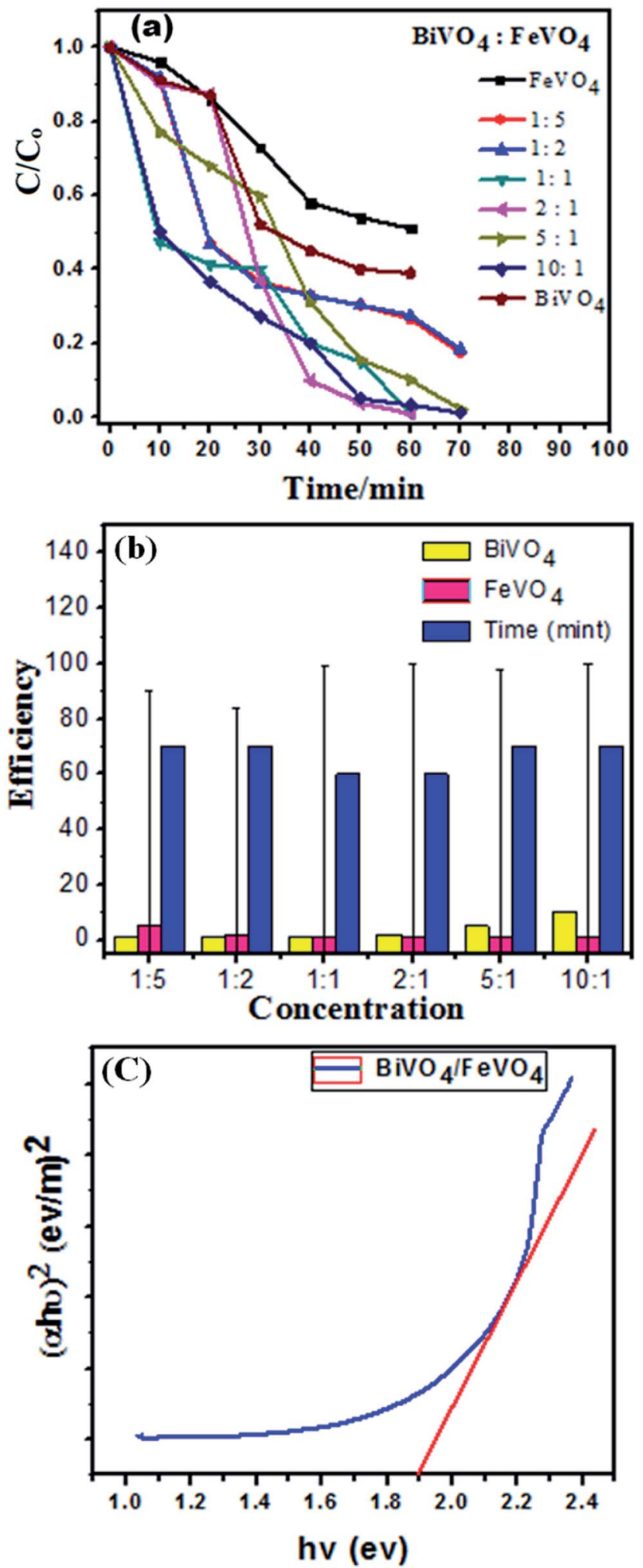

Fig. 7 (a) Concentration changes of $\mathrm{CV}$ dye as a function of irradiation time using $\mathrm{FeVO}_{4}, \mathrm{BiVO}_{4}$ and $\mathrm{BiVO}_{4} / \mathrm{FeVO}_{4}$ at molar ratios of $1: 5,1: 2$, $1: 1,2: 1,5: 1$ and $10: 1$. (b) Degradation error bar profile of CV over $\mathrm{BiVO}_{4} / \mathrm{FeVO}_{4}$ at different molar ratios as a function of time. (c) Tauc plot for $\mathrm{BiVO}_{4} / \mathrm{FeVO}_{4}$ composite with a $2: 1$ ratio. significantly higher compared to the other samples. It degraded 99.1\% of CV dye within 60 min under visible radiation illumination. It is clear that in both cases of either increasing the $\mathrm{FeVO}_{4}$ or $\mathrm{BiVO}_{4}$ molar ratio, the photocatalytic activity is reduced. However, in the case of a higher concentration of $\mathrm{FeVO}_{4}$, the photocatalytic activity first increases and then reduces.

When the molar ratio of $\mathrm{BiVO}_{4} / \mathrm{FeVO}_{4}$ is $1: 5$, the photocatalytic degradation efficiency of $\mathrm{CV}$ is $71 \%$ in $60 \mathrm{~min}$. Perhaps the most appropriate $\mathrm{BiVO}_{4} / \mathrm{FeVO}_{4}$ molar ratio to form a nanocomposite heterojunction photocatalyst is $2: 1$. The $2: 1 \mathrm{BiVO}_{4} /$ $\mathrm{FeVO}_{4}$ heterojunction photocatalyst facilitates effective electron-hole separation, reduces the recombination rate of charges and enhances the absorption of visible light. According to the above results and discussion, a higher concentration of $\mathrm{BiVO}_{4}$ or $\mathrm{FeVO}_{4}$ leads to reduced photocatalytic activity, which may be attributed to some particles of $\mathrm{BiVO}_{4}$ or $\mathrm{FeVO}_{4}$ that cannot be effectively incorporated into the composite photocatalyst. In this study, the $2: 1 \mathrm{BiVO}_{4} / \mathrm{FeVO}_{4}$ composite exhibited the highest degradation efficiency and was therefore determined to have the optimal ratio.

The degradation efficiency is determined by following the equation:

$$
\text { Degradation efficiency } \%=\left(C_{\mathrm{o}}-C_{t}\right) / C_{\mathrm{o}}
$$

where $C_{\mathrm{o}}$ is the initial concentration at the time $t_{0}$, and $C_{t}$ is the concentration at any time $t$. Fig. 7a and $\mathrm{b}$ show the degradation efficiency at the same catalyst dose. The energy band gap is an important parameter in semiconductor materials for evaluating their properties and applications, so UV-vis spectra of the prepared $\mathrm{BiVO}_{4} / \mathrm{FeVO}_{4}$ nanocomposite was calculated using the Tauc plot relation, ${ }^{49}$ as below:

$$
(\alpha h \nu)=A\left(h \nu-E_{\mathrm{g}}\right)^{n}
$$

Here, $\alpha$ is the absorption coefficient, $A$ is a constant and $n=1 / 2$ for a direct band gap material.

The energy band gap $\left(E_{\mathrm{g}}\right)$ of the $\mathrm{BiVO}_{4} / \mathrm{FeVO}_{4}$ compound was calculated by interpolating the linear portion of the plot of $(\alpha h \nu)^{2}$ versus $h v$ to the energy axis, as shown in Fig. 7c. The $E_{\mathrm{g}}$ value came out to be $1.9 \mathrm{eV}$ for $\mathrm{BiVO}_{4} / \mathrm{FeVO}_{4}$, which is closely matched to the described values. The photocatalytic mechanism for the degradation of $\mathrm{CV}$ dye solution by $\mathrm{BiVO}_{4} / \mathrm{FeVO}_{4}$ under visible light is illustrated in Fig. 8 and can be represented by the following equations:

$$
\mathrm{BiVO}_{4} / \mathrm{FeVO}_{4}+h \nu \rightarrow \mathrm{e}^{-}+\mathrm{h}^{+}+\mathrm{BiVO}_{4} / \mathrm{FeVO}_{4}
$$

Oxidation occurs at the $\mathrm{FeVO}_{4}$ surface:

$$
\begin{gathered}
\mathrm{h}^{+}+\mathrm{H}_{2} \mathrm{O} \rightarrow \cdot \mathrm{OH}+\mathrm{H}^{+} \\
2 \mathrm{~h}^{+}+2 \mathrm{H}_{2} \mathrm{O} \rightarrow 2 \mathrm{H}^{+}+\mathrm{H}_{2} \mathrm{O}_{2}
\end{gathered}
$$

Reduction reaction occurs at $\mathrm{BiVO}_{4}$ : 


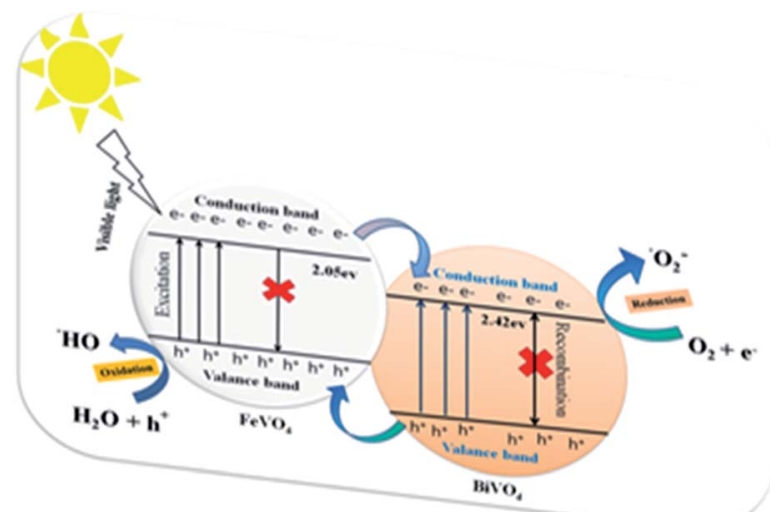

Fig. 8 Reaction mechanism of $\mathrm{CV}$ photodegradation over the $\mathrm{BiVO}_{4} /$ $\mathrm{FeVO}_{4}$ composite under visible light.

$$
\mathrm{e}^{-}+\mathrm{O}_{2} \rightarrow \mathrm{O}^{-}
$$

When visible light falls on the solution containing CV dye and the $\mathrm{BiVO}_{4} / \mathrm{FeVO}_{4}$ photocatalyst, the electrons move fast from $\mathrm{FeVO}_{4}$ to $\mathrm{BiVO}_{4}$, while the holes of $\mathrm{BiVO}_{4}$ move to the valence band (VB) of $\mathrm{FeVO}_{4}$. An oxidation reaction occurs at the $\mathrm{VB}$ of $\mathrm{FeVO}_{4}$, where positive holes react with water to form hydroxyl radicals $\left({ }^{\circ} \mathrm{OH}\right)$, while a reduction reaction occurs at the conduction band ( $\mathrm{CB}$ ) of $\mathrm{BiVO}_{4}$, where negative electrons $\left(\mathrm{e}^{-}\right)$ produce superoxide radicals $\left(\mathrm{O}_{2}{ }^{-}\right)$by reacting with dissolved oxygen. The superoxide radicals and hydroxide radicals from both ends oxidize the toxic dye $\mathrm{C}_{25} \mathrm{H}_{30} \mathrm{ClN}_{3}$ molecules and decompose them into harmless or non-toxic molecules with $\mathrm{CO}_{2}, \mathrm{H}_{2} \mathrm{O}$ and $\mathrm{NO}_{3}$ byproducts, as eqn (7) indicates below.

$$
\mathrm{C}_{25} \mathrm{H}_{30} \mathrm{ClN}_{3}+\left(\cdot \mathrm{OH}, \mathrm{O}_{2}^{-}\right) \rightarrow \mathrm{CO}_{2}+\mathrm{H}_{2} \mathrm{O}+\mathrm{NO}_{3}+\text { other }
$$
intermediates

During the photocatalysis process, various primary active species including photogenerated holes, singlet oxygen atoms, hydroxyl radicals and superoxide radicals could be created during the UV-visible degradation process. ${ }^{50-52}$ According to previous studies, in the presence of $\mathrm{N}_{2}$ and radical scavengers, ${ }^{\circ} \mathrm{OH}$ and ${ }^{\circ} \mathrm{O}_{2}{ }^{-}$are the two main active species in the entire process. ${ }^{5,45,50,52-56}$ From previous results, the dominant active oxygen species generated in direct oxidation and photocatalytic reactions are ${ }^{1} \mathrm{O}_{2}$ and ${ }^{\circ} \mathrm{OH}$ radicals. ${ }^{32,50,57,58}$ On the basis of the above studies, the probability of forming ${ }^{\circ} \mathrm{OH}$ should be much lower than that for ${ }^{\circ} \mathrm{O}_{2}{ }^{-}$; however, the hydroxyl radical is an extremely strong oxidizing agent, which takes the degradation process to either partial or complete mineralization of various organic contaminations. The photocatalytic degradation of $\mathrm{CV}$ dye by pure $\mathrm{FeVO}_{4}$, pure $\mathrm{BiVO}_{4}$ and the $\mathrm{BiVO}_{4} / \mathrm{FeVO}_{4}$ heterojunction nanophotocatalysts at molar ratios of $1: 5,1: 2,1: 1$, $2: 1,5: 1$ and $10: 1$ was performed and absorbance spectra are provided in the ESI (Fig. S4†).

On the basis of the aforementioned studies, ${ }^{5,32,52,56,58}$ once the electrons enter the conduction band of $\mathrm{BiVO}_{4}$, it induces the production of oxygen, which causes decomposition of CV dye. Hydroxyl radicals are also produced by the reaction of ${ }^{\circ} \mathrm{O}_{2}{ }^{-}$ radicals with $\mathrm{H}^{+}$ions and $\mathrm{h}^{+}$holes with $\mathrm{OH}^{-}$ions or $\mathrm{H}_{2} \mathrm{O}$. No electron paramagnetic resonance (EPR) signal was noticed when the reaction was executed in the dark. However, the signals with intensities corresponding to the characteristic peaks of DMPO- ${ }^{-} \mathrm{OH}$ and DMPO- ${ }^{-} \mathrm{O}_{2}{ }^{-}$adducts were observed during the reaction process in the EPR experiment. In Fig. 9, not only are the six characteristic peaks of the DMPO- ${ }^{-} \mathrm{O}_{2}{ }^{-}$observed, but the four characteristic peaks of the $\mathrm{DMPO}-^{-} \mathrm{OH}$ radical (1:2:2:1; quartet pattern) are also observed by irradiation of the $\mathrm{BiVO}_{4} / \mathrm{FeVO}_{4}$ heterojunction nanocomposite solution under visible light. The decay of $\mathrm{CV}$ dye by the generated oxidant species is represented by eqn (8) and (9).

$$
\begin{aligned}
& \mathrm{CV}+{ }^{\cdot} \mathrm{O}_{2}{ }^{-} \rightarrow \text { decomposed compounds } \\
& \mathrm{CV}+{ }^{\cdot} \mathrm{OH} \rightarrow \text { decomposed compounds }
\end{aligned}
$$

The effects of catalyst dose, dye concentration, stability and recyclability factors were also investigated and the results are provided in the ESI (Fig. S5 $\dagger$ ). In the absorption spectra of $\mathrm{CV}$ solution using $\mathrm{BiVO}_{4} / \mathrm{FeVO}_{4}$ at different doses of $0,2.5$ and 5 $\mathrm{mg} / 10 \mathrm{~mL}$, it is observed that the rate of degradation decreases
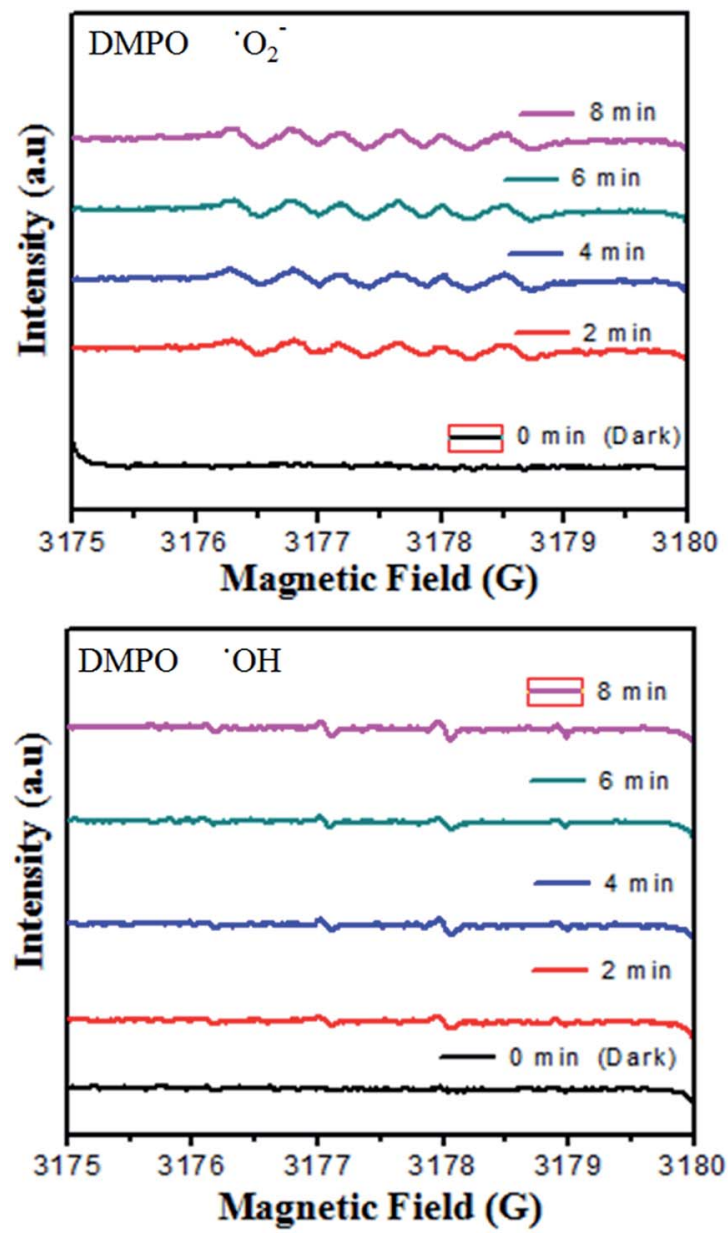

Fig. 9 DMPO spin trapping EPR spectra for DMPO- ${ }^{\cdot} \mathrm{O}_{2}{ }^{-}$and DMPO$\cdot \mathrm{OH}$ under visible light irradiation with the $\mathrm{BiVO}_{4} / \mathrm{FeVO}_{4}$ photocatalyst. 


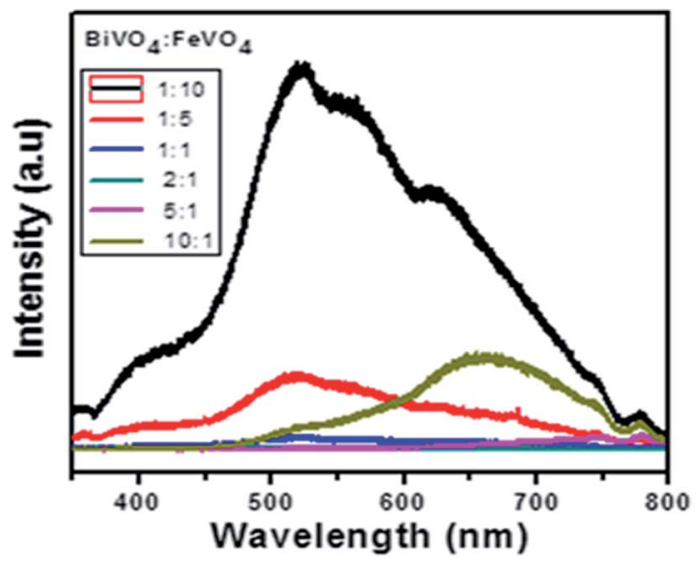

Fig. $10 \mathrm{PL}$ spectra of the $\mathrm{BiVO}_{4} / \mathrm{FeVO}_{4}$ composites at different concentrations.

as the dose of the $\mathrm{BiVO}_{4} / \mathrm{FeVO}_{4}$ decreases by $5 \mathrm{mg} / 10 \mathrm{~mL}$ to $0 \mathrm{mg} / 10 \mathrm{~mL}$ in $\mathrm{CV}$ solutions.

This implies that the amount of $\mathrm{BiVO}_{4} / \mathrm{FeVO}_{4}$ catalyst has a significant effect on the photocatalytic reaction for the decomposition of $\mathrm{CV}$ organic dye. Dye concentration effect was evaluated by taking different initial concentrations of CV dye $\left(10-50 \mathrm{mg} \mathrm{L}^{-1}\right)$ and the results are shown in Fig. S5 (ESI). $\dagger$ The color removal efficiency decreases as the CV concentration is increased; this is due to the fact that the increasing concentration of $\mathrm{CV}$ prevents light penetration into the solution. Secondly, the number of CV molecules absorbed on the catalyst surface is increased, while the numbers of $\mathrm{OH}$ and $\mathrm{O}$ radicals remain the same under specific conditions. Furthermore, the stability and recyclability of the $\mathrm{BiVO}_{4} / \mathrm{FeVO}_{4}$ heterogeneous photocatalyst were also investigated, as shown in Fig. S5 (ESI). $\dagger$ The photocatalytic activity was evaluated three times with the $\mathrm{BiVO}_{4} / \mathrm{FeVO}_{4}$ photocatalyst and the sample showed superb stability as well as recyclability.

The photoluminescence spectra exhibit the recombination rate and electron-hole separation within the photocatalysts. A higher PL intensity reveals a higher degree of electron-hole recombination, which reduces the photocatalytic degradation efficiency. ${ }^{59}$ A lower PL peak intensity indicates reduced recombination, which results in efficient charge transfer over the catalyst surface in a semiconductor. ${ }^{60,61}$ So, the low recombination allows superior dye degradation, which is consistent with the photocatalytic results shown in Fig. 10.

Electrochemical impedance spectroscopy is a versatile tool for measuring the conductivity, surface analysis and electron transfer. ${ }^{62}$ It was noticed that in all electrolytes, the impedance spectrum is either a semicircle or nearly a circle at higher ac frequency and a line at low modulation ac frequency, as shown in Fig. 11. Moreover, in the modified $\mathrm{BiVO}_{4} / \mathrm{FeVO}_{4}$ nanocomposite GCE, the diameter of the Nyquist circle decreases as compared to that of the bare GCE, indicating that the $\mathrm{BiVO}_{4} /$ $\mathrm{FeVO}_{4}$ nanocomposite exhibits much higher electron transfer on the surface and superior electrochemical activity, and as a result, the resistance decreases and improves the electron transfer process. Cyclic voltammetry was used to assess the
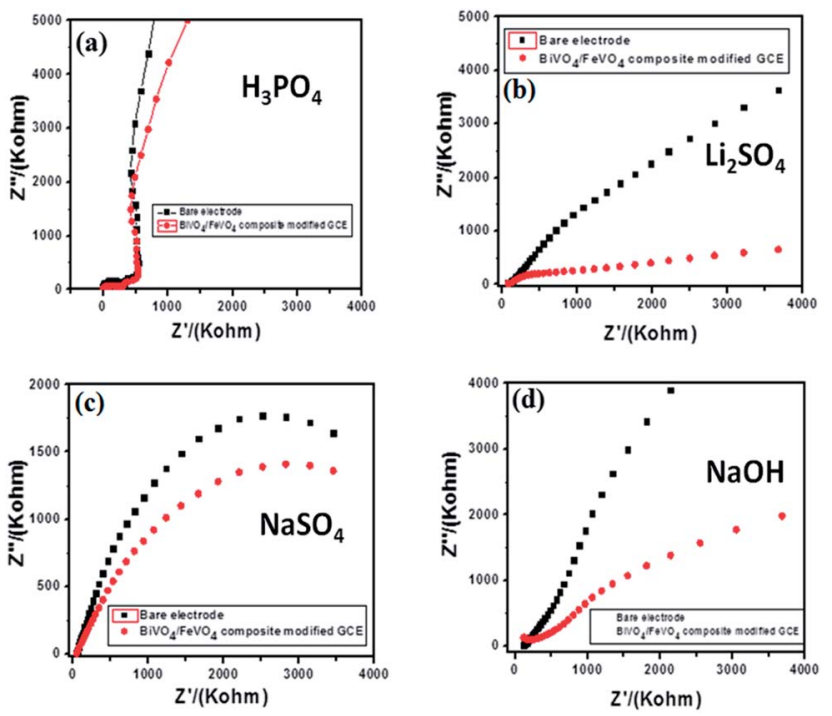

Fig. 11 Electrochemical impedance spectroscopy of bare and modified $\mathrm{BiVO}_{4} / \mathrm{FeVO}_{4}$ nanocomposite GCEs in different electrolytes: (a) $0.1 \mathrm{M} \mathrm{H}_{3} \mathrm{PO}_{4}$, (b) $0.1 \mathrm{M} \mathrm{Li}_{2} \mathrm{SO}_{4}$, (c) $0.1 \mathrm{M} \mathrm{NaSO}_{4}$ and (d) $0.1 \mathrm{M} \mathrm{NaOH}$.

detection of ascorbic acid analyte by the $\mathrm{BiVO}_{4} / \mathrm{FeVO}_{4}$ nanocomposite material. Cyclic voltammetry showed the response of the bare electrode and glassy carbon modified electrode both in the presence and absence of $0.5 \mathrm{mM}$ ascorbic acid at a scan rate of $50 \mathrm{mV} \mathrm{s}^{-1}$ at -1 to $1 \mathrm{~V} \mathrm{~s}^{-1}$ as shown in Fig. 12a. The bare electrode and modified glassy carbon electrode in $\mathrm{H}_{3} \mathrm{PO}_{4}$ solution did not show any oxidation peak both in the absence and presence of ascorbic acid. However, an enhanced current was observed, which shows that the semiconductor material has the potential to change the current intensity.

In $\mathrm{LiSO}_{4}$ solution (Fig. 12b) the bare GCE gives one oxidation peak and one reduction peak located at $0.20 \mathrm{~V}$ and $-0.20 \mathrm{~V}$,
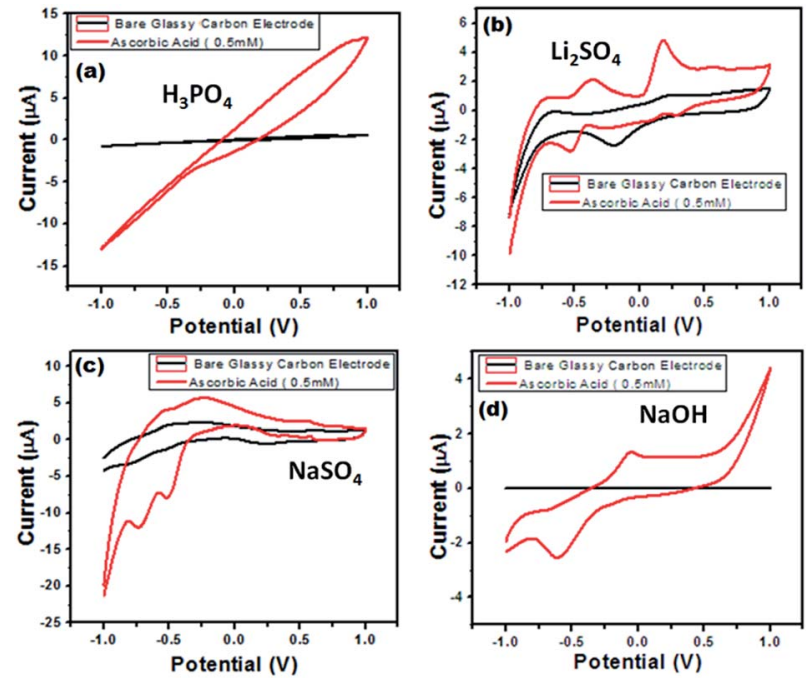

Fig. 12 Cyclic voltammograms of the $\mathrm{BiVO}_{4} / \mathrm{FeVO}_{4}$ modified GCEs in (a) $0.1 \mathrm{M} \mathrm{H}_{3} \mathrm{PO}_{4}$, (b) $0.1 \mathrm{M} \mathrm{Li}_{2} \mathrm{SO}_{4}$, (c) $0.1 \mathrm{M} \mathrm{NaSO}_{4}$ and (d) $0.1 \mathrm{M} \mathrm{NaOH}$ solution in the absence and presence of $0.5 \mathrm{mM}$ ascorbic acid. Scan rate $=50 \mathrm{mV} \mathrm{s}^{-1}$. 

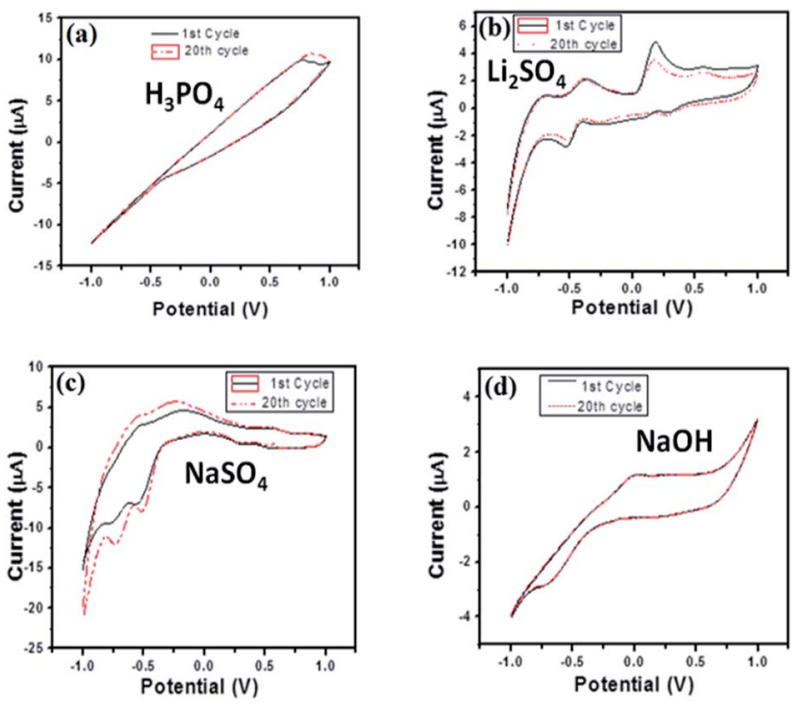

Fig. 13 Cyclic voltammograms of the $\mathrm{BiVO}_{4} / \mathrm{FeVO}_{4}$ modified GCE in mixed (a) $0.1 \mathrm{M} \mathrm{H}_{3} \mathrm{PO}_{4}$, (b) $0.1 \mathrm{M} \mathrm{Li}_{2} \mathrm{SO}_{4}$, (c) $0.1 \mathrm{M} \mathrm{NaSO}_{4}$, (d) $0.1 \mathrm{M}$ $\mathrm{NaOH}$ and ascorbic acid $(0.5 \mathrm{mM})$ solutions. Scan rate $=50 \mathrm{mV} \mathrm{s}^{-1}$. Recycling for $1^{\text {st }}$ and $20^{\text {th }}$ time.

respectively. Meanwhile, the $\mathrm{BiVO}_{4} / \mathrm{FeVO}_{4}$ nanocomposite GCE response shows two anodic peaks $(\operatorname{cvp} 1=-0.36 \mathrm{~V}, \operatorname{cvp} 2=-0.17$ $\mathrm{V})$ and two cathodic peaks $\left(\operatorname{cvp} 1^{\prime}=0.52 \mathrm{~V}, \operatorname{cvp} 2^{\prime}=0.19 \mathrm{~V}\right)$ as well as an increase in the current intensity. In the case of $\mathrm{NaSO}_{4}$ solution (Fig. 12c), the bare electrode did not show any oxidation and reduction but the modified $\mathrm{BiVO}_{4} / \mathrm{FeVO}_{4}$ nanocomposite GCE showed two anodic peaks $(\operatorname{cvp} 1=-0.49 \mathrm{~V}, \operatorname{cvp} 2=-0.71 \mathrm{~V})$. In the case of the basic solution $(\mathrm{NaOH})$, the bare GCE did not give any response, as shown in Fig. 12d. However, the modified $\mathrm{BiVO}_{4} / \mathrm{FeVO}_{4}$ nanocomposite GCE showed a change in current intensity, as well as one reduction peak (cvp $=-0.05 \mathrm{~V})$ and one oxidation peak located at cvp $=-0.59 \mathrm{~V}$.

For long-term stability confirmation we stored the modified $\mathrm{BiVO}_{4} / \mathrm{FeVO}_{4}$ nanocomposite GCE for one month at room temperature and used it for sensing ascorbic acid. It was found that it detects ascorbic acid without any decrease in current. Furthermore, we checked its reproducibility after twenty measurements, and it was found to vary slightly relative to the standard deviation of the original values, as indicated in Fig. 13. Thus, the modified $\mathrm{BiVO}_{4} / \mathrm{FeVO}_{4}$ nanocomposite GCE exhibits excellent stability and reproducibility for the electrochemical determination of ascorbic acid.

\section{Conclusions}

$\mathrm{BiVO}_{4} / \mathrm{FeVO}_{4}$ nanocomposites were synthesized via an autoclave hydrothermal method using bismuth nitrate dehydrate $\left(\mathrm{Bi}\left(\mathrm{NO}_{3}\right)_{3} \cdot 5 \mathrm{H}_{2} \mathrm{O}\right)$ and iron nitrate dehydrate $\left(\mathrm{Fe}\left(\mathrm{NO}_{3}\right)_{3} \cdot 9 \mathrm{H}_{2} \mathrm{O}\right)$ as bismuth and ferric ion sources and ammonia metavanadate $\mathrm{NH}_{4} \mathrm{VO}_{3}$ as a vanadium ion source, at different $\mathrm{BiVO}_{4}$ and $\mathrm{FeVO}_{4}$ molar ratios. The prepared nanocomposites were characterized using X-ray diffraction (XRD), scanning electron microscopy (SEM), energy dispersive X-ray spectroscopy (EDX), X-ray photoelectron spectroscopy (XPS), the Brunauer-Emmett-Teller (BET) method, Fourier transform infrared (FT-IR) spectroscopy, Raman spectroscopy, photoluminescence $(\mathrm{Pl})$, electron paramagnetic resonance, cyclic voltammetry and electrochemical impendence spectroscopy (EIS). The $\mathrm{BiVO}_{4} / \mathrm{FeVO}_{4}$ nanocomposites were investigated for their activity as nanophotocatalysts by the photocatalytic degradation of crystal violet (CV) dye under visible light irradiation. The as-synthesized heterojunction photocatalysts exhibited good photocatalytic activity, especially $\mathrm{BiVO}_{4} /$ $\mathrm{FeVO}_{4}$ at a molar ratio of $2: 1$, which showed superior degradation efficiency owing to the higher specific surface area of 70.147 $\mathrm{cm}^{2} \mathrm{~g}^{-1}$ and pore size of $3.798 \mathrm{~nm}$. The material was also studied for the electrochemical detection of an important analyte, ascorbic acid, and it showed good results. This work reveals the potential of $\mathrm{BiVO}_{4} / \mathrm{FeVO}_{4}$ nanocomposites for applications in environmental science as well as in biosensor fields.

\section{Conflicts of interest}

The authors declare no conflict of interest.

\section{Acknowledgements}

The authors are grateful to the financial support by the Basic Science Center Project of NSFC under grant No. 51788104, the National Natural Science Foundation of China (Grant No. 51572148 and 51531006), and the Tsinghua University Initiative Scientific Research Program. The present work was also supported by Ministry of Science and Technology (MoST), Govt. of Pakistan, under a program to initiate nano-biotechnology research at Government College University, Faisalabad, Pakistan. This work was also supported by Higher Education Commission (HEC) of Pakistan.

\section{Notes and references}

1 A. Houas, H. Lachheb, M. Ksibi, E. Elaloui, C. Guillard and J.-M. Herrmann, Appl. Catal., B, 2001, 31, 145-157.

2 F. Han, V. S. R. Kambala, M. Srinivasan, D. Rajarathnam and R. Naidu, Appl. Catal., A, 2009, 359, 25-40.

3 C. L. Wong, Y. N. Tan and A. R. Mohamed, J. Environ. Manage., 2011, 92, 1669-1680.

4 Y. Li, X. Yuan, Z. Wu, H. Wang, Z. Xiao, Y. Wu, X. Chen and G. Zeng, Chem. Eng. J., 2016, 303, 636-645.

5 Y.-R. Jiang, S.-Y. Chou, J.-L. Chang, S.-T. Huang, H.-P. Lin and C.-C. Chen, RSC Adv., 2015, 5, 30851-30860.

6 H. S. Peavy and G. Tchobanoglous, Environ. Eng., 1985, 628.

7 F. Sayılkan, S. Erdemoğlu, M. Asiltürk, M. Akarsu, Ş. Şener, H. Sayılkan, M. Erdemoğlu and E. Arpaç, Mater. Res. Bull., 2006, 41, 2276-2285.

8 R. Andreozzi, V. Caprio, A. Insola and R. Marotta, Catal. Today, 1999, 53, 51-59.

9 D. Wang, F. Jia, H. Wang, F. Chen, Y. Fang, W. Dong, G. Zeng, X. Li, Q. Yang and X. Yuan, J. Colloid Interface Sci., 2018, 519, 273-284.

10 R. Konta, H. Kato, H. Kobayashi and A. Kudo, Phys. Chem. Chem. Phys., 2003, 5, 3061-3065.

11 V. Conte and B. Floris, Dalton Trans., 2011, 40, 1419-1436. 
12 L. Mai, L. Xu, C. Han, X. Xu, Y. Luo, S. Zhao and Y. Zhao, Nano Lett., 2010, 10, 4750-4755.

13 S. Tokunaga, H. Kato and A. Kudo, Chem. Mater., 2001, 13, 4624-4628.

14 A. Iwase, H. Kato and A. Kudo, J. Sol. Energy Eng., 2010, 132, 021106.

15 T. Masui, T. Honda and N. Imanaka, Dyes Pigm., 2013, 99, 636-641.

16 X. Zhang, Z. Ai, F. Jia, L. Zhang, X. Fan and Z. Zou, Mater. Chem. Phys., 2007, 103, 162-167.

17 Y. Zhao, Y. Xie, X. Zhu, S. Yan and S. Wang, Chem.-Eur. J., 2008, 14, 1601-1606.

18 A. Kudo, K. Ueda, H. Kato and I. Mikami, Catal. Lett., 1998, 53, 229-230.

19 S. J. Hong, S. Lee, J. S. Jang and J. S. Lee, Energy Environ. Sci., 2011, 4, 1781-1787.

20 M. Long, W. Cai, J. Cai, B. Zhou, X. Chai and Y. Wu, J. Phys. Chem. B, 2006, 110, 20211-20216.

21 S. Shenawi-Khalil, V. Uvarov, S. Fronton, I. Popov and Y. Sasson, J. Phys. Chem. C, 2012, 116, 11004-11012.

22 M. Wang, Q. Liu and D. Zhang, Adv. Mater. Res., 2010, 129, 784-788.

23 J. Li, W. Zhao, Y. Guo, Z. Wei, M. Han, H. He, S. Yang and C. Sun, Appl. Surf. Sci., 2015, 351, 270-279.

24 M. Baojun, L. Keying, S. Weiguang and L. Wanyi, Appl. Surf. Sci., 2014, 317, 682-687.

25 C. Shifu, Z. Wei, L. Wei, Z. Huaye, Y. Xiaoling and C. Yinghao, J. Hazard. Mater., 2009, 172, 1415-1423.

26 L. Ma, S. Liang, X. L. Liu, D. J. Yang, L. Zhou and Q. Q. Wang, Adv. Funct. Mater., 2015, 25, 898-904.

27 C. Li, S. Wang, T. Wang, Y. Wei, P. Zhang and J. Gong, Small, 2014, 10, 2783-2790.

$28 \mathrm{X}$. Gao, H. B. Wu, L. Zheng, Y. Zhong, Y. Hu and X. W. D. Lou, Angew. Chem., 2014, 126, 6027-6031.

29 S. Chen, W. Zhao, W. Liu, H. Zhang, X. Yu and Y. Chen, J. Hazard. Mater., 2009, 172, 1415-1423.

30 H. Ma, X. Yang, Z. Tao, J. Liang and J. Chen, CrystEngComm, 2011, 13, 897-901.

31 C. Yu, S. Dong, J. Feng, J. Sun, L. Hu, Y. Li and J. Sun, Environ. Sci. Pollut. Res., 2014, 21, 2837-2845.

32 S.-Y. Chou, W.-H. Chung, L.-W. Chen, Y.-M. Dai, W.-Y. Lin, J.-H. Lin and C.-C. Chen, RSC Adv., 2016, 6, 82743-82758.

33 S. Gao, B. Gu, X. Jiao, Y. Sun, X. Zu, F. Yang, W. Zhu, C. Wang, Z. Feng and B. Ye, J. Am. Chem. Soc., 2017, 139, 3438-3445.

34 S. Wang, D. Li, C. Sun, S. Yang, Y. Guan and H. He, Appl. Catal., B, 2014, 144, 885-892.

35 S. Wang, Y. Guan, L. Wang, W. Zhao, H. He, J. Xiao, S. Yang and C. Sun, Appl. Catal., B, 2015, 168, 448-457.

36 S. Gu, W. Li, F. Wang, S. Wang, H. Zhou and H. Li, Appl. Catal., B, 2015, 170, 186-194.

37 W. Yang, G. Tan, J. Huang, H. Ren, A. Xia and C. Zhao, Ceram. Int., 2015, 41, 1495-1503.
38 D. Y. Chung, S. W. Jun, G. Yoon, H. Kim, J. M. Yoo, K.-S. Lee, T. Kim, H. Shin, A. K. Sinha and S. G. Kwon, J. Am. Chem. Soc., 2017, 139, 6669-6674.

39 S. S. Imam, Z. U. Zango and H. Abdullahi, Am. Sci. Res. J. Eng., Technol., Sci., 2018, 41, 26-39.

40 S. B. Khan, M. Hou, S. Shuang and Z. Zhang, Appl. Surf. Sci., 2017, 400, 184-193.

41 A. Š. Vuk, B. Orel and G. Dražič, J. Solid State Electrochem., 2001, 5, 437-449.

42 M. Alagiri, S. Ponnusamy and C. Muthamizhchelvan, J. Mater. Sci.: Mater. Electron., 2012, 23, 728-732.

43 M. Ghiyasiyan-Arani, M. Salavati-Niasari, M. Masjedi-Arani and F. Mazloom, J. Mater. Sci.: Mater. Electron., 2018, 29, 474-485.

44 P. Pookmanee, S. Kojinok and S. Phanichphant, Trans. Mater. Res. Soc. Jpn., 2014, 39, 431-434.

45 Y.-H. Lee, Y.-M. Dai, J.-Y. Fu and C.-C. Chen, Mol. Catal., 2017, 432, 196-209.

46 T. Lehnen, M. Valldor, D. Nižňanský and S. Mathur, J. Mater. Chem. A, 2014, 2, 1862-1868.

47 V. Merupo, S. Velumani, G. Oza, M. Makowska-Janusik and A. Kassiba, Mater. Sci. Semicond. Process., 2015, 31, 618-623. 48 S. Nikam and S. Joshi, RSC Adv., 2016, 6, 107463-107474.

49 P. Brack, J. S. Sagu, T. Peiris, A. McInnes, M. Senili, K. Wijayantha, F. Marken and E. Selli, Chem. Vap. Deposition, 2015, 21, 41-45.

50 W. W. Lee, C.-S. Lu, C.-W. Chuang, Y.-J. Chen, J.-Y. Fu, C.-W. Siao and C.-C. Chen, RSC Adv., 2015, 5, 23450-23463.

51 H.-P. Lin, C.-C. Chen, W. W. Lee, Y.-Y. Lai, J.-Y. Chen, Y.-Q. Chen and J.-Y. Fu, RSC Adv., 2016, 6, 2323-2336.

52 C.-T. Yang, W. W. Lee, H.-P. Lin, Y.-M. Dai, H.-T. Chi and C.-C. Chen, RSC Adv., 2016, 6, 40664-40675.

53 S.-Y. Chou, C.-C. Chen, Y.-M. Dai, J.-H. Lin and W. W. Lee, RSC Adv., 2016, 6, 33478-33491.

54 F.-Y. Liu, Y.-R. Jiang, C.-C. Chen and W. W. Lee, Catal. Today, 2018, 300, 112-123.

55 C.-W. Siao, H.-L. Chen, L.-W. Chen, J.-L. Chang, T.-W. Yeh and C.-C. Chen, J. Colloid Interface Sci., 2018, 596.

56 F.-Y. Liu, J.-H. Lin, Y.-M. Dai, L.-W. Chen, S.-T. Huang, T.-W. Yeh, J.-L. Chang and C.-C. Chen, Catal. Today, 2018, 613.

57 S.-T. Huang, Y.-R. Jiang, S.-Y. Chou, Y.-M. Dai and C.-C. Chen, J. Mol. Catal. A: Chem., 2014, 391, 105-120.

58 C.-C. Chen, C.-T. Yang, W.-H. Chung, J.-L. Chang and W.-Y. Lin, J. Taiwan Inst. Chem. Eng., 2017, 78, 157-167.

59 A. Arshad, J. Iqbal, M. Siddiq, Q. Mansoor, M. Ismail, F. Mehmood, M. Ajmal and Z. Abid, J. Appl. Phys., 2017, 121, 024901.

60 C. Shifu, Z. Wei, L. Wei and Z. Sujuan, J. Sol-Gel Sci. Technol., 2009, 50, 387-396.

61 S. Fatima, S. I. Ali, M. Z. Iqbal and S. Rizwan, $R S C A d v ., 2017$, 7, 35928-35937.

62 L. Pei, N. Lin, T. Wei, H. Liu and H. Yu, J. Mater. Chem. A, 2015, 3, 2690-2700. 